\section{Significados e práticas de saúde e doença entre a população em situação de rua em Salvador, Bahia, Brasil}

\author{
Meanings and practices associated with health \\ and illness among the homeless in Salvador, \\ Bahia State, Brazil
}

\author{
1 Instituto de Saúde Coletiva, \\ Universidade Federal da \\ Bahia, Salvador, Brasil. \\ Correspondência \\ M. M. Aguiar \\ Instituto de Saúde Coletiva, \\ Universidade Federal da \\ Bahia. \\ Rua Augusto Vianna s/n, \\ 2o andar, Campus \\ Universitário do Canela \\ Salvador, BA 40110-060, \\ Brasil. \\ mmaguiar_isc@yahoo.com.br
}

\begin{abstract}
This article aimed to analyze the practices and meanings associated with health and illness among homeless people in Salvador, Bahia State, Brazil. A qualitative anthropological study was conducted with participant observation and semi-structured interviews with 13 subjects 30 to 66 years of age. The results point to extremely precarious living and health conditions among the homeless. The narratives emphasize frequent violence. The main health problems were substance abuse, HIVIAIDS, mental disorders, and dental, dermatological, and gastrointestinal problems. Among other meanings, health was associated with the capacity to cope with everyday difficulties. Meanwhile, illness was identified as a state of weakness that hindered the struggle for survival. Homeless people only turned to health services when their health problems were serious and urgent. In conclusion, the study showed the need for specific policies to improve living conditions and access to healthcare for this population.
\end{abstract}

Homeless Persons; Population at Risk; Diagnosis of Health Situation; Anthropology
Maria Magalhães Aguiar 1

Jorge Alberto Bernstein Iriart 1

\section{Introdução}

A Pesquisa Nacional sobre População em Situação de Rua ${ }^{1}$ realizada em 71 municípios brasileiros constatou a existência de 31.922 adultos nessa situação. A grande maioria destes indivíduos $(70,9 \%)$ exerce alguma atividade remunerada, especialmente na economia informal e costuma dormir nas ruas $(69,6 \%)$. Apenas $22,1 \%$ se concentram em abrigos e $8,3 \%$ se deslocam entre ambos os espaços. Estas pessoas vivem expostas a condições de vida muito precárias, tendo dificuldade de acesso a direitos básicos da cidadania como habitação, alimentação, trabalho, higiene e saúde.

A existência de pessoas em situação de rua éum fenômeno decorrente das transformações econômicas, políticas e sociais que acometem as grandes metrópoles, em nível mundial 2. Ghirardi et al. ${ }^{3}$ afirmam que esta população sofre a marginalização provocada pelo capital, tornando-se socialmente inútil. A competição acirrada do mercado de trabalho; a fragilização dos vínculos trabalhistas pela não qualificação profissional; a inserção em atividades produtivas com grande potencial de substituição e com rendas limítrofes para a subsistência; a estigmatização pelas posições de trabalho que ocupam e o desemprego são alguns dos fatores desencadeantes desse processo $3,4,5$. Para Fernandes et al. 5, dois fatores interagem em sua determinação, um macro (tendências estruturais amplas do sistema político-econômico) e um micro (referente ao nível individual, a exem- 
plo da falta de apoio familiar). A vulnerabilidade quanto a ir para a rua decorre de um conjunto de fatores sociais, individuais e contextuais, não apenas de fatores pontuais 6 .

Escorel 7 afirma que, quando a família é anunciada como razão para a ida às ruas, alguns outros fatores geralmente estão envolvidos, como alcoolismo, violência doméstica, consumo de drogas, doenças mentais, conflitos de valores entre os membros da família, incapacidades físicas, desintegração familiar por morte de membros ou separação do cônjuge. $\mathrm{O}$ alcoolismo e o consumo de drogas interferem na unidade familiar pelos conflitos de convivência gerados pelo uso dessas substâncias, além da despesa adicional que impacta o orçamento familiar. Se a família se situa no limiar da pobreza, esse consumo pode determinar, inclusive, a desintegração da estrutura familiar. A ida para as ruas provoca uma ruptura com as formas sociais geralmente aceitas de sobrevivência segundo o princípio legitimador do mercado, no qual o trabalho é provedor da moradia, da alimentação e das demais necessidades. Viver na rua é romper com o mercado e seu estilo de vida; o que não significa a eliminação total do trabalho ou o impedimento à subsistência, mas o desenvolvimento de novos códigos, de formas específicas de garantia da sobrevivência 4 .

Nas últimas duas décadas, no entanto, em diversas cidades do Brasil e do exterior, têm surgido iniciativas, originadas da organização de pessoas em situação de rua, que buscam, através da publicação e venda de jornais elaborados por moradores e ex-moradores de rua, combinar a possibilidade de divulgação e crítica das condições experimentadas nas ruas com a oportunidade de reorganização social e econômica. No Brasil, foram realizados nos últimos anos, dois Encontros Nacionais da População em Situação de Rua que culminaram na implantação, em 2009, da Política Nacional para População de Rua ${ }^{8}$, reconhecendo a necessidade de políticas direcionadas ao enfrentamento das difíceis condições vivenciadas, que superem abordagens socialmente higienizadoras ou assistencialistas - que, em última instância, mantêm na invisibilidade as reais necessidades desta população.

A saúde, como é atualmente concebida em uma perspectiva ampla, resultante de condições de habitação, alimentação, educação, renda, trabalho, emprego, lazer, acesso a serviços de saúde, dentre outros fatores 9 , choca-se frontalmente com as condições vivenciadas em situação de rua. Questões como universalidade 10, equidade 6,10; cuidados higiênicos e curativos são extremamente distantes da realidade das pessoas em situação de rua, apesar da Constituição Federal de 1988 prever a garantia do direito à saúde a to- dos por meio de medidas que visem à diminuição dos riscos de doenças e outros agravos e o acesso universal a ações e serviços de promoção, proteção e recuperação 11 . O atendimento adequado para essa população representa um desafio a mais para o SUS e para ações intersetoriais devido a sua complexidade 6 .

Poucos estudos, no entanto, abordam a questão da saúde das pessoas em situação de rua, sobretudo na perspectiva de compreender como os indivíduos concebem o processo saúde-doença e enfrentam os problemas de saúde. Abordar os significados de saúde para as pessoas em situação de rua é, também, possibilitar um espaço de vocalização para os mesmos e suas questões; já que no contexto em que vivem, tendem a permanecer numa posição de invisibilidade, destituídos da condição de cidadãos.

Visando contribuir para diminuir esta lacuna do conhecimento e subsidiar políticas públicas voltadas para esta população, este estudo teve por objetivo, a partir de uma perspectiva antropológica, descrever as condições de vida e cotidiano nas ruas e compreender os significados e práticas associados à saúde e à doença por pessoas em situação de rua. Utilizando elementos teóricos da antropologia médica, buscou-se analisar a ação de fatores sociais e culturais na construção e na produção de formas características de pensar e agir frente à saúde e à doença ${ }^{12}$. Partiu-se do pressuposto de que a forma como a sociedade se organiza impacta diferencialmente a saúde das pessoas e grupos sociais, a distribuição das doenças na sociedade, as formas como as pessoas percebem suas condições de vida e saúde, assim como as ações individuais e coletivas para responder aos problemas de saúde 13 .

\section{Metodologia}

Trata-se de um estudo qualitativo de enfoque antropológico com realização de observação participante e entrevistas semi-estruturadas com pessoas em situação de rua.

Apesar de os termos "população de rua" e "população em situação de rua” serem encontrados na literatura, existem controvérsias quanto ao significado e a abrangência dos mesmos 3 . Apesar da multiplicidade de condições de subsistência e moradia, este grupo tende a se caracterizar por pessoas com renda bastante baixa, que por circunstância temporária ou permanente, se alojam em ruas, espaços públicos das cidades e/ ou albergues. Rosa et al. 10 (p. 2) argumentam que a expressão "pessoas em situação de rua” visa “caracterizar o princípio da transitoriedade desse processo de absoluta exclusão social, mesmo que no fundo 
muitos saibam que sair da rua não é tão simples". Neste trabalho, utilizamos a expressão "pessoas em situação de rua" 10 por denotar a possibilidade de mobilidade social ascendente ou descendente, como também em relação à transitoriedade horizontal que estes indivíduos vivenciam, podendo estar em alguns momentos abrigados em uma casa de acolhimento (ou em outros lugares), e em outros, na rua. $\mathrm{O}$ fato de estarem abrigados não os exclui de estarem "em situação de rua", caso dependam exclusivamente de um fator externo para tanto, e se, sem este, estariam nas ruas. Essa denominação também tem sido utilizada em documentos oficiais do governo, a exemplo da Pesquisa e da Política Nacional 1,8.

A observação participante foi realizada nas ruas da cidade de Salvador, Bahia, em locais de reunião de pessoas em situação de rua e em duas instituições voltadas para o atendimento desta população. As duas instituições foram um espaço de convivência-dia organizado por pessoas que já estiveram em situação de rua (Projeto Acolhimento) e uma casa mantida pelo município (Casa Amarela), que oferece abrigamento. A observação participante teve por objetivo tentar compreender a partir da imersão no contexto de vida das pessoas, como elas lidam com o corpo e a saúde no seu cotidiano e os sentidos que atribuem para as suas práticas. O trabalho de campo iniciou-se em março de 2009 e se estendeu de forma intensiva e sistemática até setembro de 2009, totalizando sete meses. Durante este período, as visitas a campo se realizavam de 3 a 4 vezes por semana em diferentes turnos e horários com registro das observações em diário de campo.

O trabalho de campo nas ruas começou com a observação realizada em praças, avenidas, viadutos, dentre outros logradouros de bairros considerados com grande concentração de pessoas em situação de rua. No decorrer do trabalho de campo, houve a tendência a situar as observações em um bairro central, onde foi possível estabelecer um contato mais próximo com algumas pessoas em situação de rua e observar suas vidas cotidianas. Com alguns interlocutores foi possível estabelecer um contato frequente, de maneira que estes reconheciam os pesquisadores e sempre se estabelecia um diálogo durante as visitas. Com outros interlocutores, no entanto, o contato foi mais esporádico dada a dificuldade de reencontrá-los novamente. A observação participante nas ruas foi limitada pela dificuldade de conseguir maior inserção entre as pessoas em situação de rua e também por questões de segurança, que restringiam a observação em determinados horários e locais menos movimentados. Os interlocutores acessados durante o trabalho de campo tinham diferentes graus de proximidade com instituições voltadas para a população em situação de rua. Alguns dormiam nas ruas, outros no abrigamento municipal (Casa Amarela), outros em um abrigamento civil (associado ao Projeto Acolhimento) e alguns frequentavam o Projeto Acolhimento em suas atividades diárias.

A observação realizada nas instituições representou uma estratégia privilegiada de inserção junto aos indivíduos em situação de rua porque foi possível ter acesso a muitos deles. O Projeto Acolhimento é mantido por uma entidade filantrópica da Arquidiocese de Salvador em parceria com o governo estadual. Ele se constitui em um centro de convivência-dia para as pessoas em situação de rua e oferece, durante as tardes da semana, atividades que visam acolher, escutar, e construir um espaço de socialização. O projeto disponibiliza também um local onde podem ter cuidados higiênicos e de saúde e encaminhamento para serviços de atenção à saúde e educação, entre outros. Dada a limitação de recursos, são acolhidas 40 pessoas a cada tarde.

Na Casa Amarela, foram observadas ações do cotidiano como almoço, lanches, residentes exercendo algumas atividades (montando bijuterias, tapetes, dentre outros), assistindo televisão, participando de reuniões, conversando nos pátios, lavando roupas, dentre outras. No Projeto Acolhimento foram observadas atividades vespertinas como reuniões, palestras, jogos e aulas de alfabetização. Durante a observação participante nas instituições, foram mantidas conversas informais sobre saúde e condições de vida das pessoas em situação de rua com membros das equipes técnicas. A equipe do Projeto Acolhimento contava com uma assistente social e cinco educadores. Na Casa Amarela tivemos acesso a uma assistente social e ao gerente administrativo do albergue. Os dados foram registrados em caderno de campo.

Para as entrevistas semi-estruturadas foram selecionados interlocutores acima de 18 anos, de ambos os sexos, que representassem a heterogeneidade da população em situação de rua (abrigados/não abrigados; participantes de projetos/não participantes; mendicantes/trabalhadores; sozinhos nas ruas/com parceiro nas ruas e tempo nas ruas). Foram realizadas entrevistas semi-estruturadas com 13 pessoas em situação de rua. Nas entrevistas foram abordadas questões relacionadas à experiência em situação de rua, especialmente quanto a questões relativas ao corpo e a saúde (cuidados com a saúde e com o corpo; manejo de doenças, dores e ferimentos; significados atribuídos ao estar na rua, à saúde e a doença, hábitos de higiene e costumes relacionados). Era inicialmente pedido aos indivíduos que contassem sua história de vida e como foram 
viver nas ruas. Na sequência, pedia-se que descrevessem o seu dia-a-dia em situação de rua. Caso as questões de saúde e corpo não aparecessem, estas eram introduzidas. As entrevistas tiveram em média duração de 1 hora. A maioria das entrevistas foi registrada com gravadores digitais ou analógicos e posteriormente transcrita.

\section{Análise dos dados}

Foi realizada uma análise de conteúdo temática voltada para a interpretação dos significados dos discursos e práticas das pessoas em situação de rua 14 . Em um primeiro momento, se procedeu à leitura exaustiva de todas as entrevistas e relatos de cadernos de campo buscando familiaridade com os dados. Em um segundo momento, no processo de codificação, buscou-se identificar indutivamente temas emergentes, padrões recorrentes e categorias nativas. As categorias analíticas incluíram os significados do estar nas ruas, a percepção das condições de higiene, significados de corpo, saúde e doença, busca de ajuda terapêutica, percepção da relação com os serviços de saúde. Entre as categorias empíricas que caracterizam a vivência em situação de rua destacam-se os significados da violência, do preconceito e desvalorização da pessoa em situação de rua recorrente nos discursos. Por fim, buscouse interpretar o discurso dos interlocutores à luz do contexto sociocultural mais amplo em que estão inseridos.

\section{Considerações éticas}

O projeto foi submetido e aprovado pelo Comitê de Ética do Instituto de Saúde Coletiva da Universidade Federal da Bahia (ISC/UFBA) tendo cumprido todas as normas da Resolução $n^{\circ}$. 196/96.

\section{Resultados e discussão}

\section{Caracterização dos interlocutores}

A maior parte dos interlocutores foi de homens com idades variando entre 30 e 66 anos, em maioria, negros, solteiros e com grau de escolaridade de Ensino Fundamental incompleto. Dos 13 indivíduos, apenas um participava de atividades tanto na Casa Amarela quanto no Projeto Acolhimento; seis não participavam de nenhuma das duas; quatro frequentavam apenas a Casa Amarela e outros quatro apenas o Projeto Acolhimento. O tempo em situação de rua variou de alguns meses até 33 anos.

As atividades desenvolvidas pelos grupos abrigados e não abrigados tenderam a se situ- ar na economia informal por meio de biscates. Apesar disto, as pessoas abrigadas aparentam estar mais assistidas quanto aos direitos sociais e quanto à possibilidade de arranjar um trabalho formal devido ao maior respaldo obtido. Inclusive, o abrigamento na Casa Amarela ou a participação no Projeto Acolhimento tende a possibilitar a busca por benefícios sociais como o Bolsa Família. Mendicância foi também relatada por alguns entre abrigados e não abrigados.

\section{Condições de vida e saúde da população em situação de rua em Salvador}

Os resultados do estudo mostram que as condições de vida e saúde das pessoas em situação de rua em Salvador são extremamente precárias. Durante o trabalho de campo foi possível observar e ouvir relatos de pessoas vivendo em viadutos, calçadas, praças, estações de ônibus ou dentro de automóveis abandonados. As casas de acolhimento da prefeitura só têm capacidade para acolher 140 pessoas de uma população estimada em 2.076.

A situação nas ruas é difícil tanto para abrigados, quanto para não abrigados. Os abrigados, no entanto, dispõem, ainda que com muitas limitações, de um mínimo de estrutura que propicia mais higiene, mais segurança e mais conforto, enquanto os não abrigados têm que invariavelmente encontrar estratégias não convencionais para a sobrevivência.

A violência aparece como uma grande preocupação para essas pessoas, principalmente à noite. Foram relatados vários casos de agressões e mortes quando as pessoas estão dormindo e o medo de ataques noturnos foi trazido em várias entrevistas. Como estratégias de proteção, algumas pessoas referiram dormir em grupo ou durante parte do dia (quando há mais movimento de transeuntes), ficando acordadas à noite, período em que as ruas estão vazias. Outros referiram dormir "de olho aberto", "sem relaxar completamente", dormir em locais diferentes dos que estiveram durante o dia ou perto de postos policiais. Esta realidade é semelhante à encontrada por Escorel 7 entre pessoas em situação de rua no Rio de Janeiro. Segundo a autora, as pessoas entrevistadas preferiam utilizar o horário da noite para atividades como comer, beber e até mesmo realizar trabalho de coleta de lixo, reservando o dia como momento de descanso por considerarem mais seguro. Walty 15 , em pesquisa realizada em Belo Horizonte, Minas Gerais, também documentou a enorme exposição à violência que este grupo vivencia, tanto sofrendo quanto cometendo tais atos. A autora acrescenta que expressões como 
"bater", "machucar", "brigar" e "prejudicar" foram muito recorrentes nos diálogos, assim como a menção a episódios de assassinatos, estupros e agressões em geral. Outras fontes de violência sofridas por esta população se relacionaram com o tratamento agressivo advindo da polícia e com a desconfiança generalizada que outros grupos sociais demonstram frente à interação com as pessoas em situação de rua.

Entre abrigados e não abrigados, a possibilidade garantida das três refeições entre os primeiros se diferencia da busca sempre constante por alimentação por aqueles que estão nas ruas. Como afirmam Ghirardi et al. ${ }^{3}$, o cotidiano da população em situação de rua está circunscrito a dois eixos, sendo o primeiro a busca por alimentos, meios para os cuidados com a higiene pessoal e lugares seguros para o descanso. $\mathrm{O}$ segundo eixo diz respeito à busca por trabalhos temporários ou atividades econômicas formais ou informais que propiciam a arrecadação de uma quantia pecuniária em troca de serviços prestados. Especialmente entre a população não abrigada, foram descritas diversas formas e estratégias para se conseguir alimentos entre as quais, doações de variadas origens (instituições de caridade, particulares ou restos de restaurantes) que nem sempre disponibilizam comida em condições adequadas de consumo; o permanecer próximo a locais que facilitem o acesso às doações; o restaurante popular (embora nem sempre tenham disponível $\mathrm{R} \$ 1,00$ para pagar) e a busca de alimentos no lixo ou em outros locais insalubres. Apesar das possibilidades descritas, alguns indivíduos relataram ter passado fome, especialmente quando recém chegados à situação de rua ou quando não dispunham de recursos para se deslocar até locais onde poderiam conseguir alimento.

“Eu como pão do lixo, eu como o que eu acho no lixo, (...) não importa como 'teja'. (...) Hoje mesmo eu nem comi, eu vou comer coisa do lixo quando eu sair pra catar â̂" (Entrevista com A., sexo feminino, 28/Ago/2009).

"Cê tá com fome (...), alguém comeu ali, largou uma quentinha, um pouco de comida, cê num [não] tá nem aí quem vai olhar assim, cê (...) come. Cê acha uma paradinha no chão, alguém pegou um pedaço e jogou, você come pra saber se vai fazer mal ou não; cê acha um alimento vencido no supermercado jogado no lixo, cê pega, cozinha, prepara e come, (...) acaba sendo uma situação que tudo aquilo que você encontra na rua é alimento" (Entrevista com Z., sexo masculino, 02/ Set/2009).

O acesso à água potável também é um problema para as pessoas em situação de rua e durante o trabalho de campo pudemos observar cenas degradantes em que estas bebiam água e lavavam suas vasilhas de comida em fontes públicas cheias de limo e sujeira.

A dificuldade na manutenção da higiene pessoal foi uma questão trazida pelos informantes como associada ao cuidado da saúde. No cotidiano nas ruas, os cuidados higiênicos como banho, escovação de dentes, raspagem de barba, lavagem de roupas são realizados geralmente de maneira precária, sem regularidade e em locais improvisados como fontes, torneiras, dique do Tororó e praias. Em geral, não são usados produtos higiênicos. Alguns interlocutores informaram utilizar produtos achados no lixo. Já, aqueles que participam do Projeto Acolhimento ou da Casa Amarela têm mais acesso à higiene pessoal, o que é destacado nos discursos como algo importante, pois permite cuidar da aparência do corpo. No dizer de um interlocutor: "pelo menos sai com a fisionomia de que (...) não é um morador de rua”, diminuindo o estigma que se abate sobre esses sujeitos.

A sujeira e o mau cheiro, no entanto, podem assumir também outros significados neste contexto. Como mostra Cefaï 16, mais do que sintoma de desleixo ou de falta de cuidado consigo mesmo, o forte odor pode representar uma forma de demarcar um território do Eu, dissuadindo intrusos de invadirem o espaço social do indivíduo. Segundo este autor, para algumas mulheres em situação de rua, o mau cheiro torna-se uma forma de proteção, funcionando como uma barreira na tentativa de evitar serem violentadas ou violadas.

\section{Saúde e doença nas ruas}

O trabalho de campo permitiu identificar um amplo leque de problemas de saúde que aflige a população em situação de rua. Entre os principais problemas de saúde referidos pelas pessoas entrevistadas encontram-se o abuso de substâncias psicoativas, HIV/AIDS, transtornos mentais/psiquiátricos, problemas odontológicos, dermatológicos e gastrointestinais. Tratou-se de questões emergentes entre indivíduos abrigados e não abrigados, contudo salientando que a condição de não abrigado possibilitava mais propensão a problemas dermatológicos e gastrointestinais porque as condições diárias de cuidado, alojamento e alimentação se mostravam mais dificultadas. Disenteria, micose, "pano" foram algumas das afecções relatadas. Como observaram Vieira et al. 4, os problemas de saúde tendem a se ampliar, especialmente os de pele causados por parasitas, em virtude da ausência de serviços de higiene (banheiros e lavanderias públicas) e das condições precárias de sobrevivência. 
O uso e abuso de substâncias psicoativas foi referido pelos interlocutores a exemplo de crack, bebidas alcoólicas, maconha e cocaína, tendo sido consideradas as duas primeiras as mais usuais. O consumo, por vezes, já existia antes da chegada às ruas, mas neste contexto foi enfatizado pelos interlocutores como forma de minimizar as dificuldades e poder suportar o sofrimento das difíceis condições de vida nas ruas. Segundo Varanda \& Adorno 2 , a ingestão do álcool é comum neste segmento, sendo referida como atenuante da percepção das rupturas sofridas e como meio de estabelecimento de laços com outros indivíduos em situação de rua.

A epidemia do HIV/AIDS e o medo de contrair o vírus foi um tema muito presente nos discursos dos interlocutores. A maioria das pessoas soropositivas não revelava sua condição sorológica dizendo que não queriam entrar em detalhes sobre determinada condição de saúde. Outros revelavam ter medo de fazer o teste e dar alguma coisa "ruim" no sangue. Alguns confirmavam que muitos deles eram portadores do HIV e durante o trabalho de campo encontramos pessoas vivendo com AIDS tanto abrigadas quanto não abrigadas. Brito et al. 17, em estudo realizado com moradores de rua em albergues de São Paulo, encontraram prevalências de 1,8\% de HIV, 8,5\% de vírus de hepatite C, 30,6\% de infecção pregressa por hepatite B. Segundo os autores, a prevalência da infecção pelo HIV encontrada no estudo representa quase três vezes a estimativa de prevalência de HIV na população brasileira.

De acordo com as observações dos pesquisadores em campo, problemas mentais/psiquiátricos se mostraram relativamente frequentes. Essa constatação entra em consonância com relatos das assistentes sociais do Projeto Acolhimento e da Casa Amarela sobre a existência de indivíduos em situação de rua apresentando diagnósticos como retardo metal leve, esquizofrenia e psicose advinda do uso de substâncias psicoativas, além de outros que permaneceram pouco esclarecidos. Em estudo recente realizado em Belo Horizonte com 245 homens adultos em situação de rua, Botti et al. 18 encontraram uma alta prevalência de sintomas depressivos (56,3\%).

Durante o trabalho de campo se tornou muito perceptível como, em geral, as pessoas em situação de rua tinham sua saúde bucal bastante comprometida e muitos já não tinham mais dentes. Entre abrigados e não abrigados foram também referidas dores diversas (nas costas, membros, coluna, ombros e cabeça), gripes, traumatismos por atropelamento, ferimentos, problemas oftalmológicos, uterinos e tuberculose. Esta última apareceu em alguns dos relatos dos interlocutores, entretanto sem sinalizar a mesma importância dada por profissionais da Casa Amarela e Projeto Acolhimento. Apesar de apontadas como muito comuns entre este grupo, nenhum dos entrevistados relatou ter doenças sexualmente transmissíveis, à exceção de dois interlocutores que declararam ter AIDS.

\section{Significados associados à saúde e à doença}

Apesar das difíceis condições de vida, as pessoas entrevistadas tenderam a fazer uma avaliação positiva de suas condições de saúde. A maioria relatou se sentir bem, ainda que alguns acrescentassem poder apresentar dores de cabeça, problemas gastrointestinais, gripes, pequenos ferimentos ou problemas de visão, dentre outros. Especialmente entre os não abrigados, esse fato pode ser em parte explicado por uma concepção de saúde que está associada à capacidade de estar vivo e de resistir ao cotidiano de dificuldades nas ruas. Já a doença foi associada ao estado de debilidade a ponto de não poder trabalhar, a impossibilidade de batalhar e ganhar dinheiro, o impedimento de realizar tarefas simples, ou no caso extremo, o organismo não suportar o sofrimento, enfraquecer e sucumbir. Entre os interlocutores que dormiam abrigados, a doença também teve um sentido de sucumbir, contudo, não necessariamente associado à questão de impedimento de atividades, mas como um acometimento ao qual, no dado momento, não se consegue reagir (segundo um dos interlocutores, nem para pedir ajuda). Tal como mostra Boltanski 19, a percepção do corpo está intimamente associada à forma como as pessoas se inserem na hierarquia social e como ganham a vida. Para as pessoas em situação de rua, o corpo é seu único bem e instrumento indispensável para a garantia da sobrevivência. Boltanski 19 afirma que a atenção que os indivíduos dão ao próprio corpo (aparência física, sensações de prazer e desprazer) cresce à medida que se eleva a hierarquia social. A percepção de saúde passa pelo corpo, sendo adaptada e legitimada pela performance corporal no cotidiano. Contrariamente, à medida que se desce na hierarquia social, há uma utilização máxima do corpo como instrumento de subsistência, através da capacidade de resistência e trabalho. Problemas de saúde que não afetassem a capacidade de trabalhar ou de locomover-se para buscar alimentos foram relativizados pelos interlocutores diante da necessidade de garantir a sobrevivência. Estes achados estão de acordo com os encontrados por Carneiro Junior et al. ${ }^{6}$ e Fernandes et al. 5, que mostram que a doença, para a população em situação de rua, geralmente tende a ser considerada como tal quando é 
aguda, demandando pronto atendimento ou quando é impeditiva de atividades cotidianas.

Já entre as pessoas abrigadas, a saúde ganha outra dimensão, incorporando a noção de zelo, associado a cuidados gerais, higiênicos e alimentares. É possível que estes por ter mais acesso a cuidados higiênicos e alimentares tendam a ampliar a noção de saúde. Entre os abrigados, a saúde foi associada a ter vida prolongada, com uma alimentação adequada (com alimentos "fortes" como feijão), a manutenção de cuidados higiênicos, zelo com o corpo e com a rotina, acompanhamento médico regular, evitar envolver-se com atividades que propiciam desgaste e com a ingestão de álcool e outras drogas.

\section{A busca de ajuda terapêutica}

Os entrevistados relataram procurar os serviços de saúde apenas quando o problema era grave e urgente. Formas de lidar com os problemas incluíram a busca de conselhos junto a pessoas próximas, o recolhimento "a um canto" para espera da remissão espontânea dos sintomas, a ingestão de bebidas alcoólicas para amenizar a percepção do incômodo e a busca de conforto na religiosidade ("ter fé em Deus"). O tratamento bucal, quando referido, tendeu a se restringir à extração dos dentes. Um dos interlocutores relatou que ele mesmo arrancou o dente que o incomodava. Varanda \& Adorno 2 constataram que muitos indivíduos em situação de rua somente se submetem a tratamentos de saúde quando são levados por serviços de resgate, por instituições assistenciais ou quando ocorre reincidência de enfermidades mal tratadas, a exemplo de casos de tuberculose.

Entre as justificativas trazidas pelos interlocutores para não recorrerem aos serviços de saúde foi referida a dificuldade de desviar tempo necessário para o trabalho/sobrevivência e também foi questionada a efetividade do atendimento médico, dado que eles iriam em seguida retornar para as ruas sem o acesso aos medicamentos prescritos e sem possuir os meios necessários para cuidar de sua saúde. A necessidade de garantir os meios de sobrevivência faz com que não possam realizar os cuidados necessários. Em campo, encontramos um interlocutor que apresentava uma fratura em um dos ossos da mão. Apesar da dor, ele havia retirado o gesso, pois necessitava movimentar os dedos para trabalhar. É possível, ainda, que o uso do gesso nas ruas represente uma mostra de indesejada vulnerabilidade perante os outros. Observou-se também que a ingestão de medicação em situação de rua, inclusive em casos de hipertensão e problemas psiquiátricos, é adaptada às circunstancias e seu uso não é regular.

A falta de documentos de identificação pessoal também foi apontada como um empecilho para o acesso aos serviços de saúde. Este fato também foi observado por Rosa et al. 10 em estudo que mostra como a exigência de comprovação de residência para definir a base territorial de atendimento termina por representar uma dificuldade a mais para as pessoas em situação de rua. Concordamos com os autores, quando defendem que a questão da territorialidade deveria ser relativizada em casos como esses para que os princípios de universalidade e equidade possam ser cumpridos.

Houve também menção à dificuldade de ter acesso a serviços de assistência como postos de saúde e SAMU (Serviço de Atendimento Móvel de Urgência) por discriminação e preconceito. Este tema, no entanto, foi pouco mencionado pelos entrevistados. Em geral, as pessoas em situação de rua relataram satisfação com o atendimento recebido quando necessitaram de assistência à saúde, o que contrastou com o relato dos técnicos do Projeto Acolhimento. Para estes, o atendimento da população em situação de rua no serviço público soteropolitano é precário e marcado pela existência de preconceito por parte de profissionais de saúde, incluindo denúncias de práticas que causam sofrimento desnecessário como a realização de suturas sem anestesia. Carneiro Junior et al. 6 encontraram em seu estudo que características como mau cheiro e sujeira serviam como justificativas para comportamentos de rejeição por parte da sociedade, reproduzidas no centro de saúde estudado, criando resistências e dificuldade no atendimento dessa população.

Dada a percepção da desvalorização social das pessoas em situação de rua evidenciada na fala de um interlocutor que revelou evitar procurar os serviços de saúde para "não incomodar os outros", é possível que a satisfação com o atendimento recebido se associe à baixa expectativa com relação ao serviço.

\section{Considerações finais}

Os dados produzidos no estudo retratam as precárias condições de vida e saúde da população em situação de rua em Salvador. Para as pessoas entrevistadas que não estão abrigadas, a saúde foi, sobretudo, associada à capacidade de resistir ao cotidiano de dificuldades, enquanto a doença vinculou-se ao estado de debilidade impeditivo de lutar pela sobrevivência. Observou-se que existem muitas barreiras que dificultam o acesso 
desta população aos serviços de saúde, que tendem a ser procurados apenas em situações graves e urgentes. Estudos recentes realizados em países com sistemas universais de saúde como o Reino Unido 20 e o Canadá 21 também mostram a existência de barreiras estruturais, tais como a inflexibilidade dos sistemas de marcação de consultas, a necessidade de documentos para acesso aos serviços, ou comportamentais como a discriminação por parte dos profissionais de saúde. Hwang et al. 21 enfatizam a importância de promover atitudes não estigmatizantes por parte destes profissionais e a necessidade de programas especiais para garantir o acesso à atenção primária para esta população. No Reino Unido, foram implementadas iniciativas na atenção primária (National Enhanced Services for Homeless People) visando prover serviços especializados e capacitados para suprir as necessidades específicas das pessoas em situação de rua 20.

Face à complexidade da situação que envolve o cuidado à saúde desta população, concordamos com Carneiro Junior et al. 6 (p. 60) quando apontam "a necessidade de criação de modelos específicos e atenção adequada a esse grupo, em que o acolhimento desta classe de usuário torne-se a questão central", tornando possível o princípio da equidade. Permanece o desafio da construção de uma rede de serviços de instituições públicas e privadas, em parceria com o Estado em busca de respostas assistenciais adequadas a esse grupo social 6 . Varanda \& Adorno 2 apontam que soluções adequadas no lidar com essa população devem superar tanto medidas repressivas de higienização das vias públicas como aquelas eminentemente assistencialistas. Torna-se fundamental considerar políticas públicas como o SUS e o princípio de equidade, propiciando abordagens flexíveis no atendimento a essa população com suas idiossincrasias. A burocracia para o agendamento de consultas e a excessiva cobrança por documentação para uma popula- ção cuja vivência cotidiana não se encaixa nos padrões sociais gerais torna-se um impedimento para o acesso destas pessoas aos serviços 6 .

A proposta do Programa Saúde da Família sem Domicílio Fixo ${ }^{8}$ pode ser uma relevante ação que urge em conciliar a promoção, prevenção e o cuidado em saúde desde a atenção básica até intervenções mais específicas com as peculiaridades deste grupo. Deve atender à necessidade de flexibilização do atendimento territorial, uma vez que essa população não necessariamente tem moradia fixa - o que fortalece a universalidade, para todos os indivíduos; e a questão da equidade, em considerar as diferenças estruturais dos usuários para oferecer serviços e ações.

Uma experiência pioneira iniciada em São Paulo em 2004 tem se mostrado bem sucedida quanto a propiciar o acesso deste grupo à atenção básica através de ações específicas face às suas necessidades e peculiaridades 22 . As ações incluem o acompanhamento de pessoas em situação de rua em seus locais de estadia, vinculando-os às unidades básicas de saúde. Há também ações de atenção à saúde nas diversas fases do ciclo de vida, com ênfase na promoção da saúde, prevenção de doenças e incentivo ao desenvolvimento de autonomia em saúde pela população. Carneiro Junior et al. 22 apontam, no entanto, a existência de desafios, como a busca de ampliação das ações dentro das perspectivas da integralidade e da intersetorialidade, que ainda necessitam ser enfrentados.

Diante dos dados apresentados, é necessário que se desenvolvam e se cumpram ações e políticas que visem alcançar melhores condições de vida e de acesso a serviços de assistência à saúde para as pessoas em situação de rua. Contudo, não se trata apenas de garantir tais êxitos, mas também de conseguir conjuntamente, que a sociedade civil, governo e demais setores tenham um novo olhar sobre estes indivíduos, se implicando em reconhecer que as necessidades deste grupo são legítimas e inalienáveis. 


\section{Resumo}

O objetivo deste trabalho foi analisar práticas e significados atribuídos à saúde e à doença pela população em situação de rua em Salvador, Bahia, Brasil. Tratase de um estudo qualitativo de enfoque antropológico com realização de observação participante e entrevistas semi-estruturadas com 13 indivíduos entre 30 e 66 anos. Os resultados apontam que as condições de vida e saúde deste grupo são muito precárias, sendo a violência sobressalente nas narrativas. Os principais problemas de saúde foram o abuso de substâncias psicoativas, HIVIAIDS, transtornos mentais, problemas odontológicos, dermatológicos e gastrointestinais. A saúde foi associada, entre outros significados, à capacidade de resistir ao cotidiano de dificuldades, enquanto a doença vinculou-se ao estado de debilidade impeditivo de lutar pela sobrevivência. Os serviços de saúde são procurados em situações graves e urgentes. Conclui-se pela necessidade de políticas específicas visando garantir condições de vida adequadas e acesso à saúde para esta população.

Sem-Teto; População de Risco; Diagnóstico da Situação em Saúde; Antropologia

\section{Referências}

1. Ministério do Desenvolvimento Social e de Combate à Fome. Pesquisa Nacional sobre a População em Situação de Rua. Brasília: Ministério do Desenvolvimento Social e de Combate à Fome; 2008.

2. Varanda W, Adorno RC. Descartáveis urbanos: discutindo a complexidade da população de rua e o desafio para políticas de saúde. Saúde Soc 2004; 13:56-69.

3. Ghirardi MG, Lopes SR, Barros DD, Galvani D. Vida na rua e cooperativismo: transitando pela produção de valores. Interface Comum Saúde Educ 2005; 9:601-10.

4. Vieira MA, Bezerra EM, Rosa CM. População de rua: quem é, como vive, como é vista. São Paulo: Editora Hucitec; 1992.

5. Fernandes F, Raizer M, Bretas A. Pobre, idoso e na rua: uma trajetória de exclusão. Rev Latinoam Enferm 2007; 15(n.spe):755-61.

\section{Colaboradores}

M. M. Aguiar realizou a pesquisa bibliográfica, o trabalho de campo, a análise dos dados e a redação do artigo. J. A. B. Iriart orientou a pesquisa, e colaborou na análise dos dados e na redação do artigo.

\section{Agradecimentos}

Às instituições em que se realizou o trabalho de campo e às pessoas em situação de rua participantes do estudo. A CAPES pela bolsa de estudos para a primeira autora.
6. Carneiro Junior N, Nogueira E, Lanferini G, Ali D, Martinelli M. Serviços de saúde e população de rua: contribuição para um debate. Saúde Soc 1998; 7:47-62.

7. Escorel S. Vidas ao léu: uma etnografia da exclusão social. Rio de Janeiro: Editora Fiocruz; 1999.

8. Ministério do Desenvolvimento Social e de Combate à Fome. Política Nacional para Inclusão Social da População em Situação de Rua para consulta pública. Brasília: Ministério do Desenvolvimento Social e de Combate à Fome; 2008.

9. Ministério da Saúde. 8a Conferência Nacional de Saúde. Relatório final. Brasília: Ministério da Saúde; 1986.

10. Rosa AS, Cavicchioli MG, Bretas AC. O processo saúde-doença-cuidado e a população em situação de rua. Rev Latinoam Enferm 2005; 13:576-82. 
11. Brasil. Constituição da República Federativa do Brasil: promulgada em 5 de outubro de 1988. 28a Ed. São Paulo: Editora Saraiva; 2001.

12. Uchoa E, Vidal JM. Antropologia médica: elementos conceituais e metodológicos para uma abordagem da saúde e da doença. Cad Saúde Pública 1994; 10:497-504.

13. Hahn R. Sickness and healing. An anthropological perspective. New Haven: Yale University Press; 1995.

14. Minayo MC. O desafio do conhecimento: pesquisa qualitativa em saúde. São Paulo: Editora Hucitec; 2007.

15. Walty I. Violência: objeto de troca. Alea 2003; 5: 83-94.

16. Cefaï D. Provações corporais: uma etnografia fenomenológica entre moradores de rua de Paris. Lua Nova 2010; (79):71-110.

17. Brito V, Parra D, Facchini R, Buchalla C. Infecção pelo HIV, hepatites $\mathrm{B}$ e C e sífilis em moradores de rua, São Paulo. Rev Saúde Pública 2007; 41:47-56.
18. Botti N, Castro C, Silva M, Silva A, Oliveira L, Castro A, et al. Prevalência de depressão entre homens adultos em situação de rua em Belo Horizonte. J Bras Psiquiatr 2010; 59:10-6.

19. Boltanski L. As classes sociais e o corpo. 3a Ed. Rio de Janeiro: Edições Graal; 1989.

20. William JL. Addressing the health needs of the homeless. Br J Community Nurs 2011; 16:134-9.

21. Hwang SW, Ueng JJ, Chiu S, Kiss A, Tolomiczenko G, Cowan L, et al. Universal health insurance and health care access for homeless persons. Am J Public Health 2010; 100:1454-61.

22. Carneiro Junior N, Jesus C, Crevelim MA. A Estratégia Saúde da Família para a equidade de acesso dirigida à população em situação de rua em grandes centros urbanos. Saúde Soc 2010; 19:709-16.

Recebido em 11/Mar/2011

Versão final reapresentada em 20/Jul/2011

Aprovado em 15/Set/2011 